\title{
Simplifying definitions of Pidgins and Creoles within the Trinidad and Tobago Context
}

\author{
Dr. Barbara D. Constance
}

Senior Instructor, The University of Trinidad and Tobago, Trinidad and Tobago

\begin{abstract}
The study of pidgins and creoles is a relatively recent field in tertiary education in Trinidad and Tobago. Many have been confused as to the relevance of this field, with few even knowing and far less understanding what these terms entail. The focus of this paper is to examine the concepts of creoles and pidgins in a simplified manner. It seeks to locate these terms within the Trinidad and Tobago landscape and, thus, remove from native Creole speakers feelings of shame and confusion. The paper, therefore, examines certain theories of origin and assesses their trajectories in modern Trinidad and Tobago Creoles.
\end{abstract}

Keywords-creoles, pidgins, contact, Trinidad English Creole, Tobago English Creole.

\section{INTRODUCTION}

In Trinidad and Tobago, the term "creole" has varying connotations including people, food and language. As it relates to people and food, the term refers to persons and foods of African origin or culture. However, the term is not regularly used by the average citizen to refer to a language. The term "pidgins" is even less known and understood. For the most part, the word "pidgin" is firstly encountered in academic circles, more specifically in linguistics subject settings.

However, even among respected linguists, there have been diverse definitions of these terms (creole and pidgin) with them being used interchangeably in some instances. In fact, the number of definitions that can be found for these terms by popular and respected linguists vividly illustrates Spears' and Winford's perspective (1997) that "There has been a long history of controversy over the definition of Pidgins and Creoles" (p. 1). He further asserts that the "identification of pidgins and creoles is based on a variety of often conflicted criteria." Also, Wardhaugh (2011) declares that even though pidgins and creoles are completely opposite, in some situations it is unclear which one is being discussed.

Before trying to ascertain what these terms mean and how to detach any ambiguity from them as individual items or as possibly interchangeable terms, it is essential that something be known of their origin. According to Is a, Halilu and Ahmed (2015),

Both languages are naturally arising in a contact situation due to lack of common language to share among group of people, and serve the purpose of lingua franca (language of wider communication). Though to some extent pidgin and lingua franca are the same. (p. 14)

Crystal's (2003) view varies somewhat, focussing rather on the content rather than on the context. He refers to pidgin as a simplified version of a language that is combined with vocabulary items of other languages. This can be interpreted as a language with reduced grammar that relies significantly on vocabulary for communication. He added that the main purpose for having a pidgin is usually for trade among persons of different cultures and languages.

In the case of Trinidad and Tobago, language contact between speakers of different native languages would have been quite prominent, including many languages that would have contributed to the languages that exist today (Winer, 1993). English, the official language, itself only became the official language in 1823 . However, what constitutes the majority language is actually an amalgamation of the various languages, referred to as a creole.

In Trinidad and Tobago, the two main languages are Trinidad English Creole (TrEC) and Tobago English Creole (TEC) respectively. While the source languages of these existing Creoles are clear, the definitions of the terms "pidgin" and "creole" and the differences between each are not as clear, with varying definitions having been put forward by linguists. Even though they may have a few commonalities, there are a number of differences. The following discourse reveals the understanding that was gained of the terms "pidgin" and "creole", as used in linguistics in the Trinidad and Tobago context. It is also an assessment of the difficulties that may arise in an attempt to define these terms. 
Pidgins

Readings on the terms help to give a sense of their definitions. UNESCO (1963) defines a pidgin as "a language that has arisen as a result of contact between peoples of different languages, usually formed from the mixing of languages", while Odimegwu (2012) defines it as an auxiliary language simplified for the purposes of communication among speakers of different native languages. Two overlapping aspects of each definition are that they both refer to the temporary time spent conversing and the fact that it was neither speaker's native language. However, neither definition takes into account certain linguistic factors which are necessary for describing a language such as it specific characteristics and functions.

Gramley (2009), however, highlights further details, defining a pidgin as "a reduced, impoverished language which is no one's native language and which is used for limited communication in situations of contact between people who do not share a native language" (p. 5). In like manner, Ching Pang (1976) explains that it is a language with restricted internal structures. Each explanation implies that the pidgin could not be described as a fully functioning language since it does not contain the complex structures that allow full languages to be used for any and every occasion. This lack of complex syntax is understandable if the main use of the pidgin is for temporary contact purposes such as trade.

Another deduction that can be drawn from Gramley's and Ching Pang's definition is that neither speaking community spends any time using the particular language since it is neither of the groups' first language or vernacular. In fact, Ching Pang (1976) asserts that certain features which usually mark established languages, for example, pluralization, tense and aspect are non-existent in pidgins. Moreover, she quotes Adler as stating that the pidgin is a "linguistic compromise between two foster parents" (Adler 1977, as cited in Ching Pang, 1976, p. 3).

These definitions have been formulated based on the historical and sociological situations surrounding the speakers. Therefore, one has to formulate an understanding based on a comparative study of the information that has been printed and orally passed on. Based on a synthesised understanding of the various definitions, a pidgin can be described as a reduced communicative structure that is forged from the necess ary limited contact between speakers of differing first languages.

This necessity of the contact can be related to trade or some other form of business that requires limited contact, thus limited communication. This 'communicative tool' that has been forged comprises a relatively small lexicon derived from the first languages of the speakers. The emerging lexicon is small as compared to the lexicon of the speakers' first languages. This is referred to as reduction as there is simply less of a language as compared to the form in which it is spoken by native speakers; the vocabulary is smaller and there are fewer syntactic structures. This is so as it contains only words that are connected with whatever the limited business may be. This can be compared to the workers' shed on a construction site, which houses the workers and the tools but does not serve all the purposes of their permanent homes.

Syntactic and morphological elements in the pidgin are even more minimal than the lexical elements. Furthermore, as with the lexical elements, the syntactic and morphological elements have been derived from the first languages. However, these are kept very basic because of the urgent need of the speakers to establish an understandable medium of communication as soon and as simply as possible to fulfil the pressing needs. There is usually need of a quick and practical structure to suit the temporary need of trading or whatever the present business pursuit may be. Furthermore, in terms of word order, pidgins do not have a fixed structure. In fact, they can have any conceivable word order, including variable order. Moreover, tense, mood and aspect (TMA) are expressed using adverbs, if at all. Also, reduplication is very rare in pidgins.

Based on the definitions, while the TrEC and the TEC must have had a starting point which could at some instance be referred to as a pidgin, there are certain reasons why they cannot be termed "pidgins". For one, the contact between the various native speakers went beyond a temporary trade interaction, to living within the same communities, howbeit in differing roles. Furthermore, the syntax and lexicon of the creole are far more extensive than the definitions given about the pidgin, rendering the TrEC and TEC suitable to be used for different functions and purposes. It may, however, be argued that at some point in the initial meeting between Spanish and the Amerindian natives in Trinidad, some level of pidgin would have been used for trading.

It could be further argued that in Trinidad, this may have continued to some extent in the early 1700s. At that point, the ratio of indigenous people to non-native Spanish dwellers was about 26:1, with there being about " 1500 native people on the missions and encomiendas" with only a small fraction of the natives being under the control of the Spanish" (Moodie-Kublalsingh, 2013). It could be theorized that some level of contact may have occurred between the independent Amerindians and the Spanish dwellers, which 
may have warranted the use of some form of pidgin for temporary contact purposes. A similar meeting of languages would have occurred with the onset of the Cedula of Population with the French migrants starting in 1783, the arrival of the British in 1797 and the arrival of the enslaved Africans starting in 1802. What is apparent is that each nationality that came would have intertwined the contributing languages even more. However, the fact that the enslaved Africans became the majority people of Trinidad, and especially Tobago, their languages must have contributed initially to some form of pidgin. In fact, Sindoni (2010) posits that:

the rapid development of a lingua franca was needed to make communication possible among slaves who were separated on their arrival in the New World from their language groups by their white masters in order to reduce collusion and possible revolts. (p. 221)

\section{Creoles}

In the case of defining creoles, the definitions evince even more confusion and disparity. In addition to the lack of established criteria is the fact that there are so many conflicting theories regarding the genesis of creoles. There is also the problem of status where the creole is simultaneously defined as a language and a dialect, thereby confusing its status and retarding its chances of attaining a position of prestige that English and other established languages enjoy.

Moreover, while there is still much that is unknown about the detailed development of most languages in the world and the history of most ethnic groups, even less has been recorded about creole languages. In many instances, they may not even be recognized (Muysken \& Smith, 1994). This lack of recognition is further exacerbated by the coexistence of the lexifier language in the territories within which the creoles are spoken as in the case of Trinidad and Tobago. More significant is that the lexifier language of the creoles in Trinidad and Tobago is the official language, termed Standard English. This has contributed to a continual comparis on being made between both codes, with the creoles being inadvertently denigrated in comparis on to the established world language, Standard English, which is viewed with respect and awe.

The lack of historical documentation, which generally occurs for the more established and esteemed languages, is even more poignant with regard to the emergence of creoles. This means that their genesis can only be studied through hypothesizing, which had led to numerous theories of origin including the European input theory, Monogenetic theory and the Afrogenesis approach.
The European Input hypothes is purports that the speakers of the supers trate lexifier languages reduced their speech when they came into contact with foreigners. This can be equated to one speaking to an infant and speaking as simply as possible for the infant to understand. If this theory were to be embraced then it means that the speakers of the substrate languages were only exposed to a fraction of the European languages. It would, therefore, logically follow that they would have filled the gaps with their original languages which at some point would have been their superstrate languages (in their native lands). What would result would be a combination of both languages with some elements from the alleged supers trate and substrate languages.

The Monogenetic theory posits that all creoles stem from the same Mother language source. More specifically, as it relates to all English-lexified creoles, Hancock hypothesises that they "descend from a single early pidgin spoken along the West African Coast in the 17th century, the so-called Guinea Coast Creole English (GCCE)" (Hancock, 1986, 1987, as cited in Migge, 2003). This theory suggests that all English Creoles are, or at least have been, similar at one point in time. Thus, in order to account for their differences, certain variables must have been present. In the case of Trinidad and Tobago, some of the factors that account for the differences in the Creoles include the historical backgrounds, where Tobago would have been colonised by many more countries, the exposure to central education, the differences in exposure to urbanity and the lack of proximity to central government.

According to the Afro-Genesis theory (Muysken \& Smith, 1994), creoles have emerged through the relexification by the slaves of the West Indian languages, the so-called substrate languages, under influence of the European colonial languages. This theory posits that creoles are actually the languages of the native Africans which have the same syntax and morphology but have the majority of the words changed to European words. If this is the case, then one would be able to superimpose the existing creoles on to the original African languages and find a structural fit with only the lexica differing. Performing this exercise today in Trinidad and Tobago today, though, would pose some challenges because the existing Creoles have changed dramatically over the years. In fact, within one generation certain structures, words and pronunciations have changed. For example, "Me eh know" has generally changed to "Ah eh know" among the younger generation. Also, terms such as "nyam" are virtually unknown to many Trinidadians and used less by younger Tobagonian speakers.

However, while the TrEC and the TEC would have changed over time, some studies suggest that there are 
actually still similarities between them and certain African languages. In fact, although they are termed English Creoles, Sindoni (2010) asserts that there are more similarities between Caribbean Creoles and African languages than with English. Structural similarities include the use of the predicative adjective with the absence of the copula such as "to be". Thus can be seen in the sentence, "She pretty", where "pretty" has the dual function of the predicate and the adjective. One of the main problems with the Afro-genesis model, though, in its strict version is the large number of structural differences between West African languages and Creoles, on the one hand, and the linguistic differences among the various West African languages themselves on the other. In spite of those differences, Dalphinis (1985, as cited by Sindoni, 2010) highlights:

thirteen common features, such as the similar use of adjectival verbs, preference for aspect-based pre-verbal markers (rather than time-based tense markers of European languages), use of stabilizers, predicative adjectives, emphatic elongation of vowels, emphatic repetition [reduplication], grammatical say/for, plural affixes, front focalisation, topicalisation, catenation, suffixation of the definite article and pronouns, nondifferentiation of the third person singular. (p. 223)

In Trinidad and Tobago, Creoles were preserved through home and community speech, with no formal recognition or regard for a long time. Creole speakers certainly did not belong to the prestigious classes among whom literacy was available and prevalent. This is supported by Ching Pang (1976) who asserts that the Trinidadian Standard English is spoken by the educated citizens who are socioeconomically advanced. Contrariwise, she posits that purer forms of the TrEC and TEC are preserved by the rural classes. Seeing, therefore, that TrEC and TEC did not constitute the language of the literate and influential, little to no encouragement would have been given to preserving its legacy in books.

This lack of historical data means that there is hardly any solid data regarding the history and development of the TrEC and TEC. This paucity of recorded data, according to Sindoni (2010), meant that "Pidgin and Creole languages were at a disadvantage because of their oral nature and their poorly documented written tradition made scholarly investigation difficult" (p. 222). However, there would be an oral perpetuation of information from varying sources based on individuals' theories, experiences, connections and biases. This could mean that, initially, researchers could use whichever theory they deemed as most logical, whether or not there might be issues with some of the facts. In spite of these apparent setbacks, though, the fact remains that creoles are alive today, with speakers spanning various generations, allowing for ongoing research, including reconstruction of past permutations through diachronic analyses.

This need for creoles to be examined and researched by native speakers is critical as it examines these notions from a first-person rather than just from a thirdperson perspective, thus balancing the reliability and attitudinal approaches to the study. This venture is essential since there are documented accounts that suggest that linguists of the nineteenth and twentieth centuries demonstrated a "eurocentric and racist attitude" towards creoles (Perl, 1995). In fact, Ching Pang (1975) penned that "derogatory, patronizing and contemptuous overtones" have been associated with the terms "pidgin" and "creole". This is further mirrored by Migge, Léglise and Bartens (2010) who posit that:

Since slaves had been assigned low social status in the colonial social hierarchy, the same connotations were also projected onto $\mathrm{P} / \mathrm{Cs}$ [pidgins and Creoles]. They were widely perceived as languages that were at best suitable for basic everyday communication in low status social domains, such as the market, the street, the village, the homes and neighborhoods of poor and socially disenfranchised populations. (p. 5)

This negative attitude was not only held by the ruling classes. It was actually also held by the native speakers of Creole who "were not willing to admit that their mother tongue was Creole, in particular in the ex-colonies, given its low prestige status and painful associations with cultural repression, feelings of self-loathing, self-contempt and failed social achievements" (Morgan, 1994 cited in Sindoni, 2010). Thus, ongoing research can help to change this inside perception and generate an attitude of acceptance and pride in what has been accomplished by those from whom this language emerged as it relates to their experiences from displacement, trauma, disregard and psychological shaming to survival, resilience and ongoing self-acceptance. Thus, instead of regarding languages such as the TrEC and TEC as "broken", "bastardised" and "unfortunate" attempts as replicating English, they can be viewed as "the core of cultural rebirth as [they constitute] the national language in the Caribbean area, incorporating at the same time painful memories of the colonial past and the resilience of survivors" (Sindoni, 2010, p. 222).

Another contributing factor to the difficulty in defining is the fact that Creole Linguistics is a relatively 
new area. This means that much more research remains to be conducted. Furthermore, many researchers in the area of Creole Linguistics either had no actual personal experience using the Creole or were not immersed in environment where Creole was the way of life. Lacking that insiders' perspective on 'pidgins' and 'Creoles' may, in fact, mean that that desire to arrive at the best possible theory or historical framework may not be a strong priority or passion for many.

\section{CONCLUSION}

Both the terms "pidgins" and "creoles" are still enigmas to many native speakers and outsiders. However, their very existence requires continual examinations of their origins, developments, functions and usage over time. This can serve to educate persons on the importance and significance of their historicity. Thus, ongoing research must be done if pidgins and creoles are to be respected and accepted, by their speakers foremost and outside communities, as viable codes of communication.

\section{REFERENCES}

[1] Ching Pang, Mary. (1976). Aspects of Trinidadian Creole. Masters' Thesis. B.A. Boston University.

[2] Crystal, D. (2003). English as a global language (2 ${ }^{\text {nd }}$ ed.). Cambridge: Cambridge University Press.

[3] Gramley, S. (2012). The history of English: An Introduction. London and New York: Routledge Taylor and Francis Group.

[4] Isa, B. Z., Halilu, K. A., \& Ahmed, H. K. (2015). The concept of pidgin and creole. Journal of Humanities and Social Science 20(3): 14-21.

[5] Migge, B. (2003). Creole formation as language contact: The case of Suriname Creoles. Amsterdam: John Benjamins.

[6] Migge, B., Léglise, I. \& Bartens, A. (2010). Creoles in education. A discussion of pertinent issues. In B. Migge, A. Bartens \& I. Léglise (Eds.), Creoles in education: A critical assessment and comparison of existing projects (pp. 1-30). Amsterdam: John Benjamins.

[7] Moodie-Kublalsingh, S. (2013). Spanish in Trinidad and Tobago. Stan, October 2012-March 2013.

[8] Muysken, P. \& Smith, N. (1994). The study of pidgin and creole languages. Amsterdam: John Benjamins Publishing Company.

[9] Odimegwu, P. (2012). A comparative analysis of Jamaican Creole and Nigerian Pidgin English. London: Odimegwu.

[10] Perl. M. \& Arends, J. (1995). Pidgins and creoles: An Introduction. Amsterdam: John Benjamins.

[11] Sindoni, M. G. (2010). Creole in the Caribbean: How oral discourse creates cultural identities. Journal des Africanistes, 80(1-2), 217-236.
[12] Spears, A. K., Winford, D., \& Society for Pidgin and Creole Linguistics. (1997). The structure and status of pidgins and creoles: Including selected papers from the meetings of the Society for Pidgin and Creole Linguistics. Amsterdam: J. Benjamins.

[13] United Nations Educational, Scientific and Cultural Organization. (1997). Sustainable development goals: Instructional manual survey of world languages. Montreal: UNESCO.

[14] Wardhaugh, R. (2011). Pidgin and creole languages. Oxford: Blackwell.

[15] Winer, L. (1993). Varieties of English around the world. Trinidad and Tobago. Amsterdam/ Philadelphia: John Benjamin's Publishing Company. 